\title{
Béroalde de Verville, La Pucelle d'Orléans restituée par Béroalde de Verville
}

\section{Dario Cecchetti}

\section{Q OpenEdition \\ 1 Journals}

\section{Edizione digitale}

URL: http://journals.openedition.org/studifrancesi/7885

DOI: $10.4000 /$ studifrancesi.7885

ISSN: 2421-5856

\section{Editore}

Rosenberg \& Sellier

\section{Edizione cartacea}

Data di pubblicazione: 1 juillet 2009

Paginazione: 383

ISSN: 0039-2944

\section{Notizia bibliografica digitale}

Dario Cecchetti, «Béroalde de Verville, La Pucelle d'Orléans restituée par Béroalde de Verville», Studi

Francesi [Online], 158 (LIII | II) | 2009, online dal 30 novembre 2015, consultato il 14 janvier 2021. URL: http://journals.openedition.org/studifrancesi/7885 ; DOI: https://doi.org/10.4000/studifrancesi.7885

Questo documento è stato generato automaticamente il 14 janvier 2021.

\section{(c) (i) (9)}

Studi Francesi è distribuita con Licenza Creative Commons Attribuzione - Non commerciale - Non opere derivate 4.0 Internazionale. 


\title{
Béroalde de Verville, La Pucelle d'Orléans restituée par Béroalde de Verville
}

\author{
Dario Cecchetti
}

\section{NOTIZIA}

BÉROALDE DE VERVILLE, La Pucelle d'Orléans restituée par Béroalde de Verville, édition établie, présentée et annotée par Corinne F. WILson et Colette H. WINN, avec la collaboration de Rafiqa AMÉZIANE et Cynthia B. MARRS, Paris, Champion, 2008 («Textes de la Renaissance», 143), pp. 430.

$1 \quad$ La Pucelle d'Orléans di Béroalde de Verville (Parigi e Tours, 1599: si tratta della stessa stampa, solo i frontespizi sono differenti) è il primo romanzo francese consacrato a Jean d'Arc. Malgrado i validi contributi di Daniela Mauri, pubblicati nella seconda metà degli anni novanta, questo testo importante rimaneva a tutt'oggi privo di un'edizione moderna. Ora viene criticamente edito da C.F. Wilson, specialista dei generi narrativi cinquecenteschi, e da C.H. Winn, specialista della scrittura femminile rinascimentale, con un'annotazione ricca e puntuale e con un utilissimo minuzioso riassunto (pp. 361-371) dei trentacinque discours in cui è suddivisa la narrazione. L'accurato glossario facilita la lettura, come pure offre un aiuto alla consultazione la dettagliata lista dei personaggi. È, questa, una delle opere più interessanti della narrativa di Béroalde, di cui presenta l'impianto abituale (discontinuità narrativa, procedimento in medias res, tecnica del flash back, anticipazioni, storie collaterali costruite simmetricamente) e il gusto per i riferimenti alchemici ed ermetici. Nella densa introduzione (pp. 7-69) le due curatrici, oltre a un profilo esauriente di dati quanto alla ricostruzione della figura di Béroalde, rintracciano il ruolo di Jean d'Arc nella letteratura francese dal Quattro al Seicento e situano La Pucelle d'Orléans nel contesto della produzione romanzesca del 
secondo Cinquecento. Vasta ed esauriente la bibliografia, che rende irrinunciabile la consultazione di questa edizione agli studiosi di Béroalde. 